\title{
Partitives, Reference to Kinds and Semantic Variation
}

\author{
Gennaro Chierchia \\ University of Milan
}

\section{Introduction.}

My objective in this paper is to provide a contrastive analysis of partitives in English and Italian. The differences between these two languages appear to be representative of the differences prevailing throughout the Romance and Germanic families and thus it is hoped that the analysis to be offered will be of more general applicability. I will couch my proposal within an approach to $\mathrm{D}$ (eterminer) $\mathrm{P}$ (hrase) structure and its crosslinguistic variation developed in Chierchia (1995b, 1996), approach which will be informally summarized below. In both Italian and English, one finds partitive constructions of the following sort:

(1) a. Some of the bottles are broken

b. Much of the wine got spilled

c. Most of the country is in favor

d. Alcune delle bottiglie sono rotte

'Some of-the bottles are broken'

e. Molto del vino si e' rovesciato

'Much of-the wine REFL PAST spill'

Much of the wine got spilled

f. La maggior parte del paese e' a favore

' The largest part of-the country is in favor'

Most of the country is in favor

In these structures (which I will call "Full Partitives") a certain class of determiners is followed by an of-phrase containing a definite DP. Full Partitives appear to be completely parallel in Italian and English in their basic empirical properties (that are fairly well documented -- see, e.g. Selkirk 1977 or Abney 1987). Note just a minor difference, as it will play a role in our analysis: in Italian, but not in English, the article $i$ cliticizes onto the preposition $d i$ forming what is known as a "Preposizione Articolata".

In Italian next to Full Partitives one also finds the following related constructions:

(2) a. Delle bottiglie sono rotte 'of-the bottles are broken' Some bottles are broken

b. Del vino si e' rovesciato

'of-the wine REFL PAST spill'

Some wine got spilled

c. * Del paese e' a favore 'of-the country is in favor'

Most of the country is in favor

Here we see the same preposition+definite article complex that shows up in Full Partitives, but without a determiner. It is as if the preposition+article complex had been itself promoted to the status of an autonomous determiner with an 
indefinite/existential meaning. I will refer to the structures in (2) as "Bare Partitives". Note that while Full Partitives admit plural, mass and singular count nouns, Bare Partitives admit only the former two while disallowing singular count nouns (compare (1f) with (2c)). Bare Partitives are attested in several of the Romance languages (like Italian, French or Rumanian), while other languages of the Romance family (like Spanish or Portuguese) disallow them and have a plural form of the indefinite article instead (cf. Spanish unos 'aMAS-PL'). Throughout the Germanic family, Bare Partitives appear to be disallowed. The absence of Bare Partitives in Germanic appears to constitute a major typological contrast between the two language families, presumably to be linked to other differences in their respective nominal structures. In particular, it is well known that the distribution of bare nominals (bare plurals and bare mass nouns) is much freer in Germanic than in Romance:
a. Water is dripping from the faucet
b. Dogs are barking in the courtyard
c. * Acqua sta gocciolando dal rubinetto
d. * Cani stanno abbaiando in cortile

The Italian sentences $(3 c-d)$, which are the literal glosses of the English sentences (3a-b), are ungrammatical. Presumably, the availability of Bare Partitives, which are close (though not perfect -- see below) functional counterparts of bare nominals, is related to the unavailability of the latter. One would like to understand how exactly this correlation is to be conceptualized in terms of the architecture of DP structure. These considerations show that partitives are interesting not only for their own sake, but also for the light they shed on how DP structure can vary crosslinguistically. both syntactically and semantically. A good theory of DP structure ought to derive in a principled manner the typological contrasts just mentioned.

The present paper is organized as follows. Since Bare Partitives appear to be related to bare plurals and bare mass nouns, I will begin by sketching in section 2 some general assumptions concerning plurals and the mass/count distinction. Starting with the ground breaking work of Carlson (1977), bare nominals have been shown to be the main device English uses for referring to kinds. Thus some assumptions as to how kinds enter into the picture will have to be also laid out. I will then sketch, in section 3, a general picture of how languages may vary in their way of referring to kinds and of encoding plurality and the mass/count distinction. This is based on Chierchia $(1995 b, 1996)$ and will provide us with a framework, within which the differences in the partitive structures of Germanic vs. Romance can be, I will argue, optimally understood. The analysis will come in two parts. The first, which given the limits of the present paper will have to be necessarily sketchy, will concern the different distributions of bare nominals in English vs. Italian (section 4). The second, more detailed, will concern the specifics of Full and Bare Partitives (section 5). The line of analysis that will emerge, if it turns out to be on the right track, will have far reaching consequences (laid out in section 6) concerning how semantic variation is to be conceptualized. In particular, it will support the view that a certain (tightly limited) amount of parametrization occurs not just in syntax but also in the syntax-semantics map. I will try to make a case that an economical design of grammar must countenance such parametrization. 


\section{Plurals, mass, and kinds}

Following much recent research (see e.g. Link 1983, Landman 1991, Schwarzchild 1996) let us assume that the domain U of interpretation forms a complete, atomic, join semilattice, to be visualized as follows:

$$
\begin{gathered}
\{a, b, c\} \\
\{a, b\} \quad\{a, c\} \quad\{b, c\} \quad \ldots
\end{gathered}
$$

a $\quad b \quad c$

The letters at the bottom in (4) represent singularities. Pluralities are modeled as sets. The structure is ordered by a part-of relation ' $\leq$ ' in the natural way. A singular definite NP like the boy in the corner will denote a singularity, while a plural definite DP like the students in my class will denote a plurality. Singular count common nouns denote characteristic functions true or false of singularities. Plural count nouns characteristic functions true or false of pluralities. This is illustrated in what follows.

$$
\begin{aligned}
& \text { (5) } \begin{array}{l}
\text { a. } \\
\operatorname{dogs}_{\mathrm{w}}
\end{array}=\left[\begin{array}{ccc}
\{\mathrm{f}, & \mathrm{b} & , \mathrm{s}\} \\
\{\mathrm{f}, \mathrm{b}\} & \{\mathrm{b}, \mathrm{s}\} & \{\mathrm{f}, \mathrm{s}\}
\end{array}\right] \\
& \operatorname{dog}_{\mathrm{W}}=\quad\left[\begin{array}{llll}
\mathrm{f} & \mathrm{b} & \mathrm{s}
\end{array}\right] \\
& \mathrm{f}=\text { fido } \quad \mathrm{b}=\text { barky } \quad \mathrm{s}=\text { spotty } \\
& \text { b. } P L=\lambda P \lambda x[\neg P(x) \wedge \forall \mathrm{y}[\mathrm{y} \leq \mathrm{At} x \rightarrow P(\mathrm{x})]]
\end{aligned}
$$

Assuming that Fido, Barky and Spotty are all the dogs there are in a world or situation $\mathrm{w}$, the denotations of the common noun $d o g$ and its plural counterpart dogs will be as shown in (5a). The semantics of the plural morpheme is given in (5b). ${ }^{1}$ These assumptions on plurals are fairly standard. Less standard is the line we will take on mass nouns. Following the proposal put forth in Chierchia (1995b), mass nouns will be taken to be the neutralization of the singular/plural contrast. The things that a mass noun can be true of in a world include indifferently singularities and groups thereof. Thus, for example, if table a, chair $b$ and couch $c$ are all the pieces of furniture there are in a given world $w$, then the extension of the common noun furniture in $\mathrm{w}$ will be:

$$
\stackrel{\text { (6) }}{\text { furniture }}=\left[\begin{array}{ccc}
\{\mathrm{a}, \mathrm{b}, \mathrm{c}\} \\
\{\mathrm{a}, \mathrm{b}\} & \{\mathrm{b}, \mathrm{c}\} & \{\mathrm{a}, \mathrm{c}\} \\
\mathrm{a} & \mathrm{b} & \mathrm{c}
\end{array}\right]
$$

Mass nouns like water have exactly the same structure, except that the minimal parts of water are considerably vaguer than those of furniture. Depending on the context, a molecule, a drop, or some other amount can qualify as a minimal part of water.

In Chierchia (1995b) it is argued that the empirical contrasts associated with the mass/count distinction can be naturally explained in terms of this 
minimal assumption. For example, the impossibility of pluralizing mass nouns can be seen as a consequence of the fact that in a sense they already have plural structure. As the reader can easily check, the function PL in (5b) would, in fact, yield the empty set applied to any predicate with the structure in (6). As for the impossibility of combining mass nouns directly with numerals (cf.. *three furniture), it can be imputed to the fact that to count one needs to identify a suitable level at which counting can take place. Such a level is generally provided by a set of presupposed or forgrounded singularities. In the present set up, it is very easy to see what a "presupposed" or "forgrounded" singularity is: what the lexical entry singles out. A count lexical entry like dog singles out a set of singularities, which, we may reasonably assume, is a necessary requirement for counting. A mass lexical entry like furniture does not, as it applies to any amount of furniture. This, we may in turn assume, makes it unsuitable for counting. To combine a numeral with a mass noun, we need either a measure phrase (like three pounds of) or else something that maps mass noun denotations into a set of singularities. Classifier phrases (like piece of) appear to play just such role. One might go on and show how all the other properties associated with the mass/count contrast can be derived from the assumption exemplified in (6). But the remarks just made, though cursory, should suffice to give the reader the flavor of how the basic idea works. The most straightforward argument in its favor is an economy one: the approach just sketched, unlike its rivals, does not posit any structure specific to mass nouns. At the same time, it retains all the advantages of theories that do. For example, it has been argued (see Sharvy 1980, Link 1983) that a strong point in favor of positing a mass algebra next to a count one has to do with the treatment of the definite article. The can be interpreted in terms of a maximality operator " $\mathrm{l}$ " such that for any predicate $\mathrm{P}, \mathrm{lP}$ gives us the maximal individual satisfying the predicate, if there is one. Thus, if $\mathrm{P}$ is plural or mass, $\mathrm{lP}$ will yield the greatest aggregate $\mathrm{P}$ applies to (on the respective domains). If $\mathrm{P}$ is singular, $\mathrm{lP}$ will be defined only if $\mathrm{P}$ is true of exactly one thing (for no singularity is "bigger" in the relevant sense than any other singularity). This arguably explains well why phrases like the fumiture in that room or the boys in the corner refer to maximal aggregates, while the boy standing in the corner is defined only if the boy in question is unique. This idea, which was viewed as argument for imposing a join-structure on the mass algebra parallel to the one for plurals, can obviously be executed also on our approach to the mass/count distinction, using just a "count" domain. The structure revealed by the singular/plural contrast suffices to explain also what is special about mass nouns.

If the domain has the structure in (4), what are kinds? For example, what is in any given world, the dog-kind? A natural enough move is to identify it with the totality of dogs, i.e. the scattered individual that comprises all of the dogs as its parts. More explicitly, the dog-kind as such can be thought of as an individual concept that yields, in any world $w$, the maximal plural individual comprising all of the dogs (see Ojeda 1993 for a similar view). Of course not any old individual concept is a kind. In particular, an individual concept that yields a singularity in any world, is not a kind: a kind in the relevant sense should be able to have more than one instance. To make another example, the function that in any world yields Clinton's right toe, Eco's copy of War and Peace and my pet red fish is unlikely to constitute a kind. Kinds must group individuals by some "natural" criterion. 
Given the set of kinds $\mathrm{K} \subseteq \mathrm{UW}^{\mathrm{W}}$ and assuming $\mathrm{K}$ to live in $\mathrm{U}, 2$ we can define a function that maps a predicate $\mathrm{P}$ into the corresponding kind $\cap \mathrm{P}$ (if there is one).

$$
\begin{aligned}
& \text { a. For any world } w \text { and any property } \mathrm{P} \text { : } \\
& \cap \mathrm{P}_{\mathrm{w}}=\lambda \mathrm{w}\left[\mathrm{l} \mathrm{P}_{\mathrm{w}}\right] \text {, if } \lambda \mathrm{w}\left[\mathrm{lP} \mathrm{P}_{\mathrm{w}}\right] \in \mathrm{K} \text {; else undefined. }
\end{aligned}
$$

Examples

b. $\cap$ dog $=$ undefined

(since, for any world $w,\left[\log _{w}\right]$ is a singularity and kinds cannot

be uniquely instantiated in every possible world)

c. $\cap \operatorname{dogs}=\lambda w\left[\operatorname{lPL}(\operatorname{dog})_{\mathrm{w}}\right]=$ in any $w$, the totality of dogs in $w$

d. $\cap_{w a t e r}=\lambda w\left[\right.$ lwater $\left._{w}\right]=$ in any $w$, the totality of water in $w$

The operator ' $\cap$ ' can be viewed as an explicit definition (limited to common noun denotations) of Chierchia's (1984) "nominalization" functor. An inverse operator ' $\checkmark$ 'can easily be defined for any kind $d$, by taking (for any world $w$ ) the ideal generated by $\mathrm{d}$ in $\mathrm{w}$.

$$
\begin{aligned}
& \text { For any kind } d \text { and any world } w \text {, } \\
& \cup_{d_{W}}=\lambda x\left[x \leq d_{w}\right] \text {, if } d_{w} \text { is defined, } \lambda w[\varnothing] \text {, otherwise. }
\end{aligned}
$$

A straightforward computation reveals that if $\mathrm{P}$ is a mass property, then $\cup \cap \mathrm{P}=$ $\mathrm{P}$. This does not hold, on the other hand, if $\mathrm{P}$ is a plural count property. For a plural property $\mathrm{P}$ does not apply to atoms, while, as the reader can easily check, $u \cap P$ does. In a sense, $\cup \cap P$ results in a "massification" (in our terms) of $P$. This apparent little quirk, which follows from defining ' $U$ ' as an ideal forming operator, will turn out to have useful consequences.

\section{A Typology of Noun Denotation}

What do common nouns (and common noun phrases) denote? Tradition has it that common nouns are to be thought of as predicates and hence be semantically associated with properties. However, it is also conceivable, and it has occasionally been proposed (see e.g. Krifka 1995), that they denote kinds. This means that, a priori, we have three logical possibilities: nouns may uniformly be predicates, or they may uniformly be kind denoting, or, possibly, some nouns might go one way and others the other way. The dominant tradition tends to be very universalistic: there is only one right answer to this question and whatever that maybe it's the same for all languages. Chierchia $(1995 \mathrm{~b}, 1996)$ explores instead the alternative view that languages may vary on exactly such score. Here is, in brief, the gist of that proposal.

Let us think of the category-type association in terms of two features: $\pm \arg ($ umental) and \pm pred(dicative). If $\mathrm{N}$ is + predicate, it means that members of that category can be predicates (i.e. of type $<\mathrm{e}, \mathrm{t}>$ ); if $\mathrm{N}$ is -pred, it means that they cannot. Similarly for the feature \pm arg (where the argumental types are the type e of entities and the type GQ of generalized quantifiers). Now, excluding the [-arg-pred] option, which would leave nouns without a denotation, we have the following three possibilities: 


$$
\text { a. } \quad \text { NP }
$$

b. NP

$[-\arg +$ pred $]$ c. NP

[+arg +pred]

Let us consider these options in turn, beginning with the one in (10a). In a language with such a setting, nouns can be arguments and cannot be predicates. Thus, every noun has to be kind denoting. This has some immediate consequences. The first and most obvious one is that in such a language, bare nouns, being argumental, should be able to occur in the canonical argumental positions (subject, object, etc.). So in such a language, one ought to be able to say things l like "I saw bear", meaning roughly "I saw the bear-kind". Moreover, nouns, whatever their basic type, are also universally amenable to predicative uses. The prototypical ones are in predicate positions (as in the equivalent of I consider [John a friend]) and as quantifier restrictions (as in every man = everything which is a man). So even in a language with the setting (10a), it will be necessary to turn kinds into predicates. The operator that does that is ' $\cup$ '. But, as we saw, such an operator only creates predicates that are mass. So in this language, every lexical noun (when used predicatively) will get a mass extension. This means that plural morphology (i.e. a morpheme meaning PL that attaches to a noun stem), being incompatible with mass denotations, will be altogether absent (i.e. undefined for every predicate). And numerals won't be able to attach directly to nouns, for the same reasons one can't say "three furniture". In order to combine nouns with numerals, the language will need a system of classifiers capable of covering the whole vocabulary. Summing up, a language in which every noun is kind denoting should have the following characteristics:

(11) a. Free occurrence of bare (determinerless) arguments

b. Absence of plural morphology

c. Impossibility of combining numerals directly with nouns

d. Generalized system of classifiers

As is well known, languages with exactly these characteristics abound: Chinese, Japanese, Thai, etc. What is interesting is that although the properties in (11) are per se not logically related, under the present approach to (un)countability and kinds they do follow in a unitary way just from the setting in $(10 a)$.

Let us consider, next the setting in (10b) which essentially says that all (lexical and phrasal) members of category $\mathrm{N}$ are predicates. What properties would we expect such languages to have? First and formost, since predicates are not of the right type for being taken as arguments by other (ordinary) predicates, one would not expect to see bare nominals in the canonical argumental slots. Or, at the very least, whenever we see a noun occurring bare in argumental position, we have to assume that some null operator (say, a null determiner) has changed its basic type into an argumental one. But null operators and, in general null structure, is subject to licensing conditions that limit their distribution. Hence, in a language with the setting in (10b) there either shouldn't be bare arguments, or they should have the typical distribution of null elements (e.g. ECP-like phenomenology). Moreover, nouns in such a language are free to be either mass or count, as that has to do with the different way in which the extension of predicates is set. If a noun denotes a set of atoms, it will combine directly with numerals; it will also be able to take plural morphology (which will allow it to refer to groups of atoms of the relevant

kind). If, on the other hand, a noun comes out of the lexicon denoting the $\cup$ - 
closure of a set of atoms, it will have the properties that nouns seems to have in Chinese type languages: no numerals without classifiers and no plural. Thus we get:

(12) a. No or highly restricted occurrence of bare arguments

b. Count nouns with plural morphology and the possibility of directly combining with numerals

c. Mass nouns without plural morphology

d. Classifiers obligatory only for mass nouns

Again, what is interesting is that the underlying interdependence of a cluster of seemingly unrelated features emerges naturally, under the present view, just from the assumption that all nouns are predicates. Now, these properties seem to characterize pretty accurately the major typological traits of the nominal system in Romance. In French, bare arguments are basically always out. In Italian or Spanish they have a limited distribution, which has been argued to be subject to the ECP (see Contreras 1986, Torrego 1989). Throughout Romance, the mass-count contrast has the features sketched in (12).

The final possibility is (10c). In a language of this kind, members of category $\mathrm{N}$ can be either predicates or names of kinds. This means that lexical entries will be free to chose between these two options. If a noun is kind denoting, it should have the same properties as Chinese nouns; and hence it should come out as mass. If a noun is a predicate, it should be count and have the same properties as a French noun. So, bare mass nominal arguments should be possible, while bare (singular) count nominal arguments should not be possible. In a sense, a language with the setting in $(10 \mathrm{c})$ should be the union of the Chinese and the Romance system; the first should characterize mass nouns, the latter the count ones. This is, of course, what seems to happen in Germanic, as the following English examples illustrate:
a. I want water
b. * I want chair

There is a further consequence that also flows naturally from the assumption that in certain languages nouns can be freely arguments or predicates. If there are automatic, costless ways of changing a predicate into an argument (and vice versa), it should be possible to use them freely, as the category-type association allows nouns to be of either type. Thus, particular the language should be free to resort to the nominalization function ' $\mathrm{n}$ '. A noun born as a predicate $\mathrm{P}$ can be turned into the corresponding kind $\cap \mathrm{P}$. However, the nominalization operator is defined only for plurals. Hence, only bare plural arguments, will be grammatical in such a language and will be used as a device for kind reference.

dogs are widespread $==>$ widespread $(\cap P L(\operatorname{dog}))$

To sum up, the setting in (10c) yields the following cluster of properties:

(15) a. Mass/count contrast (as in Romance)

b. Bare mass arguments

c. Bare count plural arguments

d. No bare count singular arguments

One of the assumptions we have used in deriving this pattern from the setting in $(10 \mathrm{c})$ is free use of type shifting, under the fairly plausible assumption that this 
is allowed by the category-type mapping. The nominalization operator, however, is not the only natural way to shift the type of predicates to that of arguments. For example, Partee (1987) proposes the following as plausible ways of shifting types:

$$
\begin{aligned}
& \text { Type shifting from }<\mathrm{e}, \mathrm{t}>\text { into e or GQ } \\
& \text { a. } \cap: \cap P=\text { the kind corresponding to } P \quad \text { [inverse: } \cup \text { ] } \\
& \text { b. } \mathrm{l}: \mathrm{lP}=\text { the maximal element in } \mathrm{P} \quad \text { [inverse: Ident] } \\
& \text { c. } \exists: \exists \mathrm{P}=\lambda \mathrm{P} \exists \mathrm{x}[\mathrm{P}(\mathrm{x}) \wedge \mathrm{Q}(\mathrm{x})] \quad \text { [inverse: } \mathrm{BE} \text { ] }
\end{aligned}
$$

Type shifting operations all have a natural inverse (and, hence, their effects can be undone) and appear to be necessary for the semantics of a variety of constructions (see Partee 1987 for details). The question that arises is the following. Shouldn't we expect that a language with the setting in (10c) should allow free use of all the type shifting operations that grammar makes available? To answer this question, we have to figure out what properties such a language would have. Essentially, such a language would allow for bare singular arguments (as ' $\mathrm{l}$ ' and ' $\exists$ ' are defined for singulars as well as for plurals) with an definitee or a indefinite meaning. I.e. in such a language one ought to find sentences of the following kind:

$$
\begin{aligned}
& \text { a. boy walked in }==>\exists \text { boy }(\text { walk in })=\text { some boy walked in } \\
& \text { b. boy walked in }==>\text { walk in (lboy) }=\text { the boy walked in }
\end{aligned}
$$

Sentences like (17a-b) are ungrammatical in Germanic. However, there are languages where they are grammatical, for example Latin or many Slavic languages, like Russian. Russian has the singular-plural contrast as well as the mass-count one, like English. Bare plurals are used for kind reference. Bare singular arguments are also possible, with both a definite or an indefinite meaning depending on the context. This further typological difference between English and Russian might have a very simple explanation: type shifting is a kind of "last resort". One uses it, if the grammar doesn't make available other options. If a language has a morpheme or construction whose meaning is a certain type shifting operation, then "covert" use of that operation is blocked. English (and all the Germanic languages) have the articles. The meaning of the definite article is arguably the functor ' 1 '. The meaning of the indef inite article is, arguably, the functor ' $\exists$ '. Therefore, covert use of these operations is banned. Whence the ungrammaticality of (17a-b). Russian lacks articles, nor does it have other devices whose semantics can be assimilated to ' $l$ ' or ' $\exists$ '. Whence the grammaticality of the Russian counterparts of (17a-b). Otherwise, Russian and English are alike in the semantic mapping of their nominal systems.

Even though this is all very sketchy, a rather systematic general picture clearly emerges. Minimal changes in the mapping between the syntactic category $\mathrm{N}$ and its meaning produce different clusterings of properties that appear to characterize different languages. If nouns are all names of kind, we get the Chinese type. If nouns are all predicates, we get Romance. If nouns can be either, we get the Germanic/Slavic kind. A number of logically unrelated features reveal, in this way, their underlying connectedness. Notice, that the setting prevailing in a language might be leamable, in principle, in the same way 
as any other grammatical difference: through its concrete morphosyntactic manifestation. The most restrictive setting appears to be the Chinese-like one, as it bans plural morphology altogether. So that might be plausibly taken as the default case. Children might start taking the Chinese setting for the nominal system. This might constitute an interesting account as for why they use so extensively bare arguments. Such a use would not be "defective" or an instance of some kind of "truncated structure", but a perfectly sensible category-type correspondence, attested in many languages of the world. If their language turns out not to be of this kind, upon encountering plural morphology (or upon seeing that numerals can directly combine with nominal heads), children would be able to modify their original assumption by direct positive evidence alone. The next most restrictive option is the Romance one, as it bans (or severely restricts) the occurrence of bare arguments. So the next assumption that children may make is that nouns are predicates. The persistence of bare arguments (of various sorts) in a language like English would eventually lead children to figure out that they are in language of the "mixed" kind. This means that the English speaking child will take longer to converge to the final stage of DP grammar than, say, a French speaking one, as whether a noun is kind-denoting (and hence mass) or not will have to be determined case by case for each lexical entry. Whether these expectations are borne out remains to be seen (although a preliminary perusal of the CHILDES data base encourages optimism).

The reader will surely be aware that so far this is armchair acquisition. Nonetheless, these considerations do show that the present hypothesis does make falsifiable and non trivial predictions for acquisition and that the variations in the category-type mappings appear to be in principle as learnable as any other form of grammatical variation.

\section{Bare arguments in Romance vs. Germanic.}

To better substantiate the picture sketched in section 3 , I will discuss a bit more the differences in the distribution of bare arguments in English vs. Italian. This will set the stage further for the analysis of partitives. There is a substantive and interesting body of literature on the topic of bare arguments and it will be impossible to do justice to it within the limits of the present paper. I will first discuss the case of English. Then I will contrast it with what happens in Italian.

\subsection{Bare Arguments in English}

Clearly, the assumption that the types of nouns in English lets them denote kinds leads squarely to what might be called a Neocarlsonian view of kinds. According to Carlson, bare arguments (whether plurals or mass) reveal their true nature in sentences like (14). These sentences show that bare arguments can happily combine with kind selecting arguments, which can be construed as evidence that bare plurals/mass indeed are just names of kinds. However, this leaves us with the task of accounting for their behavior with predicates that are not kind-selecting. Carlson classifies the latter into two major types: episodic and generic. In episodic sentences, bare plurals are interpreted as (weak) existential indefinites; in generic ones they tend to be interpreted as if they were universally quantified. ${ }^{3}$ Carlson's proposals concerning non kind selecting predicates can be couched, for our present purposes, in the following somewhat updated form. Essentially, a sentence like (18a) ought to be interpreted by analogy with (18b): 
(18) a. I saw lions in the zoo

b. [Pointing at the picture of a lion in a zoology book] I saw that in the zoo

c. $[\text { see }]_{\mathrm{k}}(\mathrm{I}, \cap$ lions $)=\exists \mathrm{x}[\mathrm{\cup} \cap \operatorname{lions}(\mathrm{x}) \wedge \operatorname{saw}(\mathrm{I}, \mathrm{x})]$

Uncontroversially, the natural interpretation of the demonstrative that in (18b) is not as referring to a particular lion, but to the kind as such. The sentence is grammatical because evidently verbs like "see", which primarily apply to objects, (one sees concrete particulars) can also be applied, in a perhaps derivative way, to kinds. Whatever mechanism is at work in (18b), call it "Derived Kind Predication" (DKP), will also be at work in (18a), under the assumption that bare plurals denote kinds. For explicitness sake, we may assume that an operator [ $]_{\mathrm{k}}$ changes (episodic) object-level predicates into kindlevel ones by quantifying over instances of the kind, as indicated in (18c). This operator is applied as needed to resolve type mismatches when they arise. Plausibly, this operator is made available by Universal Grammar (as part of a very small set of analogous operators). It remains to be seen whether languages may vary in the way DKP is used.

As for generic contexts, where bare arguments are interpreted universally, the analogy is with sentences like (19a):

(19) a. This kind of animal feeds on ants

b. Porcupines feed on ants

c. Gn x [ Unporcupines(x)] [feed on ants(x)]

In (19a) we have a (definite) kind-level subject yielding a quasi universal interpretation. According to much recent work, genericity is imputed to a quantificational element usually indicated as $G n$, akin to adverbs of quantification, licensed by the aspectual system of the verb. The generic operator is dyadic; it has a restriction and a scope and quantifies over instances of the elements in its restriction. This is sketched in (19c). The capacity of adverbs of quantification of "introducing variables" of the appropriate sort is well documented. Cf. for instance a sentence like (20) where the quantificational force of the definite plural subject clearly varies with the choice of adverbial phrase:

(20) Those boys are all/for the greatest part/only in small part Italian

Again, under the assumption that bare plural unambiguously denote kinds. whatever device is at work in (19a) or (20) cannot fail to extend to sentences like (19b), resulting in a universal readings over instances of the kind.

The approach which emerges is remarkably simple. ${ }^{4}$ The behavior of bare plurals can be wholly accounted for under the minimal assumption that they name kinds (plus independently needed devices, like DKP and the grammar of genericity and quantificational adverbs). One the strongest arguments besides simplicity in favor of this view has to do with the fact that it predicts with great accuracy the scopal and anaphoric properties of the existential readings of bare plurals. On the present view, existential readings arise via DKP. Overt indefinites are subject to mechanisms of scope assignments (and/or rules of existential closure in Discourse Representation Theory and related frameworks). But clearly, an existential quantifier introduced via DKP will not be subject to such rules and will always have a 
maximally local scope. Thus we expect bare plurals to contrast systematically with (weak or strong) indefinites in this respect. This seems to be exactly so and was a crucial part of the evidence originally put forth by Carlson. I report here some of it.

(21) a. Opacity

i. Lee wants to meet policemen

ii. Lee wants to meet a policeman

b. Narrow scope.

i. Lee didn't see a spot on the floor

ii. Lee didn't see spots on the floor

c. Differentiated scope

i. Lee killed a rabbit repeatedly

ii. Lee killed rabbits repeatedly

d. Anaphora.

i. Lee is trying to find some policemen and Kim is trying to find them too ii. Lee is trying to find some policemen and Kim is trying to find them too [only opaque]

[both opaque and transparent]

[two readings: $\neg \exists, \exists \neg$ ]

[one reading: $\neg \exists$ ]

[narrow scope for repeatedly] [wide scope for repeatedly] [narrow scope for some policemen]

I will refer to these properties jointly as the "scopelessness" of bare plurals. Their import of (21a-d) should be self explanatory. Consider, for example, the interaction with negation illustrated in (2lb). Under negation, overt indefinites display two possible readings, which standard theories of scoping will readily make available. For bare plurals, we find only one option. The existential quantifier can only have narrow scope with respect to negation. This is what one would expect under the present analysis. The existential quantifier is introduced with local scope over the verb by DKP. Assigning wide scope to the bare plural won't change this fact, as bare plurals being like proper names won't be affected by scoping. In fact, if Fox (1995) is right, scoping of proper names (whether of individuals or of kinds) will generally be ruled out by economy.

It can be argued that the present approach takes us a few steps beyond Carlson's original proposal. A fact noted by Carlson himself was that not all bare plurals display scopelessness. Carlson discusses nominals like parts of that machines, books that John lost yesterday, people sitting in the next room, etc. that seem to contrast systematically with bare plurals of the more ordinary type. The following paradigm illustrates the relevant phenomenon:
a. Lee is looking for parts to that machine
[ambiguous]
b. Lee didn't see parts to that machine [ambiguous]
c. Lee killed people sitting here repeatedly [narrow scope for adv] $\mathrm{d}$. Lee is looking for parts to that machine and Kim is looking for them too
[wide scope for parts to that machine]

With respect to the properties in (21), nominals like parts to that machine pattern with overt indefinites rather than with bare plurals. They enter the same scope dependencies as existentially quantified NP's. Carlson argues that there is no syntactic property which is common to nominals like the one in (22). The only thing one can notice is that it is hard to conceive of parts to that machine or people sitting in the next room as a kind. This is confirmed by the oddity of these nominals with kind-level predicates: 
The situation which emerges is the following. All basic (common) nouns can be associated with a kind. Modified common nouns may or may not, depending on whether the resulting class is sufficiently "natural" (which, to a certain degree, will be subject to variation from language to language and possibly, even from context to context). If a common noun doesn't have a corresponding kind, it is interpreted in the same way as overt indefinites (i.e. as an existentially quantified nominal). On Carlson's approach this had to be stipulated. More recent DRT-inspired approaches, which hold that bare plurals are ambiguous between a kind reading and a weak indef inite one (see, e.g. Krifka (1988) or Diesing (1992)) if anything fare even worse. They would have to stipulate that if the nominal head is kind denoting, the existential quantifier that gets associated with it is always narrow scope; if on the other hand the noun is not kind denoting, the existential quantifier can be either narrow or wide scope with respect to other scope bearing elements. On the present theory, here is what happens. If a property $\mathrm{P}$ doesn't have a corresponding kind, $\cap \mathrm{P}$ will be undefined. Thus, in particular, , parts to that machine will be undefined. At this point, we are free to resort to another type shifting operation. The plural definite article blocks using ' $l$ '. This leaves us with ' $\exists$ '. As English lacks a plural indefinite article, nothing blocks using ' $\exists$ ' as a type-shifter. Hence non kind denoting nominals wind up as full blown existentially quantified nominals.

The account just sketched, raises a couple of issues that need to be addressed. The first is concerns the relation between ' $\mathrm{A}$ ' and ' $\exists$ '. If they are both available as type shifters for plurals, why is ' $n$ ' chosen in (22)? It seems that ' $\cap$ ' is first choice and ' $\exists$ ' is used only when ' $n$ ' fails (i.e. only for the arguments for which ' $\cap$ ' is undefined). The answer to this could be quite simple. There is a clear sense in which ' $n$ ' alters the meaning of its arguments more minimally than ' $\exists$ '. In fact, ' $\cap$ ' merely changes the type of its input. More specifically, under our construal, a property $\mathrm{P}$ is a function from worlds into characteristic functions; $\cap \mathrm{P}$ is a function from worlds into the corresponding sets (i.e. the maximal plural individual of which $P$ is true). Thus, in an obvious sense, the information associated with $\mathrm{P}$ is only minimally altered: it is (roughly) the difference between characteristic functions and the corresponding sets. ' $\exists$ ', on the other hand, clearly changes the meaning of its input more radically. Thus, the preference for ' $\cap$ ' over ' $\exists$ ' is just a preference for minimal change, which seems plausible. On the other hand, when ' $n$ ' is undefined, ' $\exists$ ' remains the only available way of shifting from argument to predicates.

The second issue that arises is the following: in English there is a live morpheme, generally taken to be a device of existential quantification, that applies also plurals, namely some. Why doesn't its presence block use of ' $\exists$ ' as a type shifter? One line of answer might be that the use of type shifting as a last resort is a markedness criterion: it sets defaults that can be overridden at a cost. While that might well be the case in general, for the case at hand it might not be necessary. Indefinites have long been known to have very special scopal properties. In particular, they seem not to obey the locality conditions that other quantifiers obey to. Recently, the idea has emerged that this may be due to the fact that their semantics involves choice functions (see e.g. Reinhart 1995, 
Kratzer 1995, Winter 1996, and references therein). If these theories are on the right track, some would not be the overt realization of ' $\exists$ '. Consequently, one would not expect it to block use of ' $\exists$ ' as a type shifter. However, these considerations, one might object, should apply also to the indefinite article $a$. Also the latter escapes island and has been argued on this basis to involve choice functions. One might therefore be inclined to conclude that if some doesn't block ' $\exists$ ', $a$ shouldn't either. But then, ' $\exists$ ' should always be freely available for type shifting in languages with the same category-type mapping as English. And since ' $\cap$ ' is always undefined for singulars, we should be free to use ' $\exists$ ' with them. However, as we saw, in English this doesn't seem to happen. It happens in Russian, which lacks the indef inite article. Thus it seems that $a$, unlike some, does act as a blocker. This seems to entail that, if the present approach is on the right track, the situation must be the following: $a$ is ambiguous; on the one hand it means ' $\exists$ ' on the other it is interpreted as a choice function; per contrast, some is unambiguous: it only has the choice function interpretation. Then, it would make sense that the indefinite article should indeed block covert uses of ' $\exists$ ' for the items in its domain; while a determiner like some should not. Which is what in fact happens. I tentatively conclude that this is indeed so: $a$ is ambiguous, some is not.

This conclusion on the differences between $a$ and some is of course highly speculative. Indefinites are rich and complex structures and we cannot come even close to making them justice here. There is, however, a very simple consideration that lends plausibility to the conclusions we have tentatively reached. Generic readings are generally assumed to be obtained from existential ones. For example, in Chierchia (1995a), indefinites are interpreted as dynamic existential quantifiers that are then further operated on by adverbs of quantification and/or by the generic operator. As is well known, while the indefinite article readily admits of generic interpretations, some does not.

(24) a. A cat usually is intelligent

b. Some cat usually is intelligent

The natural interpretation of $(24 a)$ is a statement on cats in general (something like: "most cats are intelligent"), (24b) lacks such interpretation. Under the view that $a$ is ambiguous between and existential and a choice function reading, while some only has the latter one, this difference can be explained on the basis of an independently plausible theory of genericity. There is no obvious way to obtain generic readings out of choice functions, while there are well explored routes that show how to obtain them out of existential readings. Since $a$ admits of the latter, while some does not, the contrast in (24) is as it should be.

Taking stock, under the assumption that some, for independent reasons does not block use of ' $\exists$ ' as a type shifter, the contrast between (22) and (23) is predicted. Nothing specific to it needs to be assumed. ' $\cap$ ' is the unmarked way to shift types; when it is undefined for some argument, one resorts to whatever else is available. For English plural NP's, ' $\exists$ ' is the only choice. On the present view of how the category-type mapping works, one can stick to a truly minimal story on the behavior of bare arguments in languages like English. 


\subsection{Bare Arguments in Italian}

There is no complete agreement on what the basic empirical generalizations are in Romance. Here I will have to limit myself to present the main facts as I see and understand them. In French, basically there are no bare arguments. In Italian, their distribution is limited to lexically governed positions:

a. Leo, di mestiere, stermina ratti 'Leo, by profession, exterminates rats'

b. Leo ieri si e' incontrato con amici 'Leo yesterday met with friends'

c. * ragazze sono rare 'girls are rare'

d. *sono rare ragazze 'are rare girls'
$\mathrm{V}$

$\mathrm{P}$

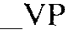

VP.

In object position or as object of a preposition (both of which are the canonical lexically governed positions) bare plurals are fine. In subject position (both preand postverbal), where no lexical head governs, bare arguments are out. Bare nominals can also occur in the clause initial focus/topic position (cf. 26a-b) or can be rescued in positions where they would normally be banned by making them "heavy" (26c):
a. RAGAZZE sono rare, non ragazzi
FOCUS
'GIRLS are rare, not boys'
c. ragazze non ne ho viste 'girls not of-them (I) saw
b. ragazze in minigonna sono rare Heaviness 'girls in miniskirt are rare'

Sentences (26) illustrate what the rescue strategies for Italian bare arguments are. The first involves moving the offending bare nominal to a clause initial Focus/Topic position as in (26a-b) (where the latter is the Clitic Left Dislocation position -- cf.. Cinque 1990; on the syntax of $n e$, see e.g. Cardinaletti and Giusti 1992). The second involves making the NP "heavy", e.g. by the addition of a modifier as in (26c).

When grammatical, bare nominals appear to have the same range of readings as English. For example, they are grammatical with kind selecting predicates (cf. (25a) or (26a-c)). They display the $\exists / \forall$ alternation in episodic vs. generic contexts; and they display scopelessness and suspension thereof under the same conditions as English. The following minimal pair illustrates the latter property:

a. Non ho incontrato persone interessanti [only $\neg \exists$ ] (I) didn't meet interesting people

b. Non ho incontrato persone interessanti che avrei voluto incontrare (I) didn't meet interesting people that I would have liked to meet [both $\neg \exists$ and $\exists \neg$ ]

The NP interesting people acts as if it was kind denoting; the NP interesting people I wanted to meet patterns with overt indefinites in its scopal properties. 
Here is how to account for this range of facts within the theory sketched in section 3. According to our mapping hypothesis, the category $\mathrm{N}$ in Romance is predicative. Thus, unlike what happens in Germanic, members of category $\mathbf{N}$ cannot be shifted to an argumental type within $\mathrm{N}$. The syntactic category has to change as well: an NP must be turned into a DP. We must, in other words, assume the presence of a null determiner $\partial$ that acts as syntactic support for type shifting. If this is so, there are further consequences. Null structure must be somehow "flagged". Using Rizzi's proposal (1986), or whatever subsumes its effects under more current assumptions, a null element is subject to a condition for licensing and a condition for identification. In Romance the condition for the licensing of $\partial$ appears to be closeness to a suitable head. The one for identification appears to be sharing of plural features with the complement noun. This explains why in French, which lacks phonologically identifiable plural features on the noun, the null D is unavailable (a fact discussed in Delfitto and Schroten 1992). In Italian, suitable heads for the licensing of $\partial$ are either lexical heads or the functional heads FOC and TOP (see Rizzi 1996 for a recent discussion of the left periphery of the clause). A bare nominal in the spec position of these heads is grammatical. Movement to these spec positions can be either overt, i.e. pre-spell out, as in (26a-b) or covert, i.e. post spell out, as in (26c), assuming "heaviness" to be a necessary condition for the latter. One way of thinking about this is in terms of a feature $+F$ that (i) triggers movement to a suitable head in the left periphery -- pre or post spell out and (ii) is interpreted phonologically either as stress or as an intonational contour that requires "enough stuff" to get realized by the phonetic interface.

Semantically, the null $\partial$ is interpreted as SHIFT; since Italian has the

same blockers as English, the unmarked choice will be ' $\cap$ '; the language will

resort to ' $\exists$ ', when ' $\cap$ ' is undefined (i.e. for predicates that do not have a kind as their argumental correlate). In this way, a fairly complicated pattern gets explained in terms of very little machinery, that, moreover, seems largely to be in place on independent grounds. The differences between English and Italian boil down to the fact that $\mathrm{D}$ must be always projected in Italian to turn a noun into an argument (given the difference in type assignment). Further differences follow from independent licensing conditions on phonologically null structure.

The present approach has a further interesting consequence worth pointing at, however briefly. Consider the case of proper names, which we haven't discussed at all. Generally, proper names are taken to be expressions that refer to (ordinary) individuals. Thus the overwhelmingly unmarked tendency for proper names is that of being argumental: proper names are the prototypical arguments. Now in languages like Chinese or English, whose type assignment lets $\mathrm{N}$ be of an argumental type, proper names can happily satisfy their universal tendency to being referential: nothing gets in the way of their being of type e. But what about Romance? These languages set the type of $\mathrm{N}$ to $<\mathrm{e}, \mathrm{t}\rangle$. So a clash arises. The unmarked status of proper nouns (i.e. their being of type e) cannot be realized within the category $\mathrm{N}$ (or its projections). This seems to entail that proper names in Romance, unlike common nouns, ought to be displaced from their original position and moved to an argumental position, the closest one being the category $D$. In other words, proper nouns ought be reanalyzed as determiners, yielding a structure of the form [D Leo [N e ] ], where the empty category indicates the base position of members of category $\mathrm{N}$. This tantamounts to assuming that proper names (and only proper names) undergo a process of head raising that promotes them to the status of determiners. This process has in fact been detected by Longobardi (1994, 
1995). The evidence is fairly straightforward distributional evidence. Romance has just a handful of prenominal adjectives, i.e. adjectives that can occur to the left of head nouns (most of the adjectives being postnominal). Proper names (and only proper names) when they occur without a determiner occur to the left of prenominal adjectives, i.e. in the $\mathrm{D}$ position. The following pattern, taken from Longobardi, illustrates:

a. La sola Milano e' stata prescelta

'The only-fem Milan was chosen'

b. *Sola Milano e' stata prescelta

Only-fem Milan was chosen

c. Milano sola e' stata prescelta

Milan only-fem was chosen

Solo/-a with gender marking is an adjectival counterpart of only. In (28a), Milano is analyzed as a common noun and the determiner is obligatory (cf. the ungrammaticality of (28b)). In (28c), the proper noun occupies visibly the D position, to the left of the prenominal adjective sola. On our theory, this movement is triggered by the incompatibility between the type associated with category $\mathbf{N}$ in Romance and the unmarked type of proper names (which, however, can also be semantically reanalyzed as predicates as in (28a)). Longobardi argues that head movement for proper names occurs throughout Romance and is altogether absent in Germanic. From our point of view, this makes a lot of sense. Not only our hypothesis on the semantic mapping of nominal categories enables us to account for the limited distribution of bare arguments in Romance in a simple way. It also predicts that $\mathrm{N}$ to $\mathrm{D}$ raising is necessary for proper nouns in Romance and impossible in Germanic.

\section{Partitives}

Having now some idea of how the different nominal systems of Germanic vs. Romance might work, we can address the issue of partitives. Let us begin with full partitives. An idea that, in various forms has been around for some time analyses phrases like those in (29) along the lines shown in (30) (the illustration is given with both English and Italian data).

(29) a. Three of the boys

b. Tre dei ragazzi

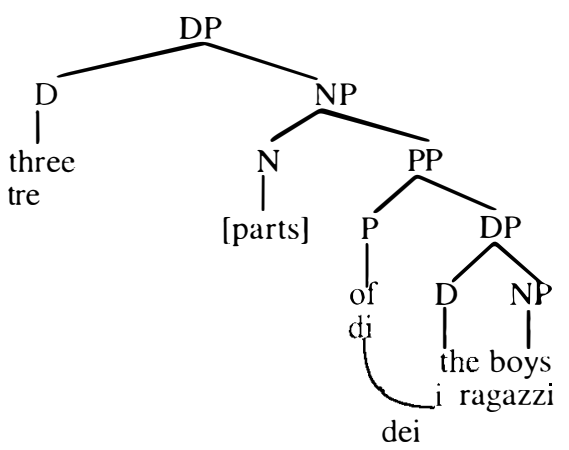


In this structure we assume the presence of a null nominal head, to be interpreted as a relational noun, something like "part" or "component". Such a noun takes a PP complement. The main reason for making such an assumption is that it regularizes the structure of Full Partitives, reducing it to an otherwise attested construction and it makes sense of its semantics. This null nominal head, we may assume, is licensed (selected) by a subclass of the determiners (the numerals, all, everyone, but not the articles, every, etc.). The preposition of is there for syntactic (case theoretic) reasons. The complement of the relational noun must be definite, something the present theory has not much to say on (but see Ladusaw 1982). The interpretation of the definite article is the canonical one. Here are the main steps in the derivation of the interpretation of (30):

$$
\begin{aligned}
& \text { a. the boys }==>\text { tboys } \\
& \text { b. } \operatorname{part} \text { of the boys }==>\operatorname{part}(\text { lboys })=\lambda x[\operatorname{part}(x, \text { boys })] \\
& \text { c. three of the boys }==>\text { three }(\operatorname{part}(\text { lboys }))
\end{aligned}
$$

The natural way in to interpret "part" is in terms of the relation $\leq$. However, other interpretations are also possible as attested by the fact that definite singulars that have salient natural parts are admitted in Full Partitives (many of that group, most of the country, etc.). A moment of reflection reveals that in any situation with two or more boys, the denotation of "parts of the boys" is the same as "boys"; in any situation with less than two boys, "boys" is empty while "parts of the boys" is undefined. This difference is due to the presence of the definite article the in the partitive and has the consequence of making phrases like one of the boys undefined in situations where it is known that there is no more than one boy, which seems correct. As mentioned at the outset, there is nothing particularly original to the present analysis of Full Partitives.

The structure of Italian partitives seems to be roughly the same as its English counterpart, as evidentiated in (30). The only difference is that the definite article $i$ cliticizes onto the preposition di giving rise to dei. Presumably, this is not a syntactic process, but a purely phonetic one. The reason why in general the formation of preposizioni articolate is not to be thought of as a syntactic incorporation is that such incorporation of $\mathrm{D}$ into $\mathrm{P}$, besides violating, in the given order, the Mirror Principle of Baker (1988), would also destroy the canonical D-NP configuration, which is arguably necessary for feature checking.

There is, however, a possible way of circumventing this block; and this is the way that, I want to suggest, Bare Partitives take. We observed that what happens with Bare Partitives is that a preposizione articolata is promoted to the status of full determiner, with an indefinite meaning roughly equivalent to the plural of the indefinite article. It is implausible that what we are facing here is just an idiosyncratic lexical process. For one thing, this would make it accidental that the preposition we find in Bare Partitives is the same found in Full Partitives. Moreover, it would remain completely mysterious, on such a view, why a preposition+article complex involving the definite article winds up having an indefinite meaning. These weaknesses urge us to look for an alternative analysis.

Let us take a closer look at the possibility of syntactic incorporation. Normally, we cannot raise $\mathrm{D}$ into $\mathrm{P}$ for the reasons stated above. Suppose, however, it was possible to reconstruct right above the preposizione articolata the canonical D-NP configuration necessary for checking. Then the main 
obstacle to incorporation (i.e. to the syntactic promotion of the preposizione articolata to D status) would be removed. This requires a reachable D-NP position right above the preposizione articolata. But that is just what we have in full partitives. So the kind of raising illustrated right below appears to be, after all, possible:

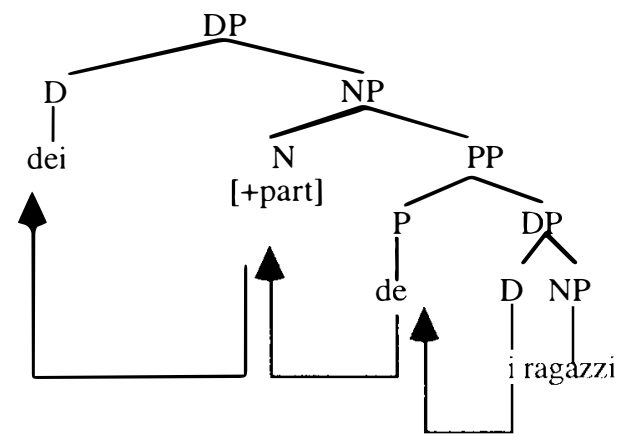

First, the article incorporates into $\mathrm{P}$; then the resulting complex incorporates into the empty $\mathrm{N}$; finally the result incorporates into the higher D position. Through this upwards fuga, the preposizione articolata becomes a determiner. The canonical D-NP relation can be maintained (either because the upward movement makes transparent the relation between the upper D and the lower nominal head ragazzi, or because the lower nominal head in turns raises into the upper one). The trigger of the first step might be a clitic feature (call it $\mathrm{CL}$ ) that the definite article may have and that can drive it to cliticize onto $\mathrm{P}$. This is not so surprising, for clitics in Romance are always homophonous with definite determiners. The further steps in (32) (i.e. $\mathrm{P}$ to $\mathrm{N}$ and $\mathrm{N}$ to $\mathrm{D}$ ) are driven by the ordinary $\phi$-features of the determiner (i.e. gender and number) that have to be checked in the canonical way in which determiners and their nominal arguments check their respective features. 5

How does the semantics work? The preposition of by itself has no meaning. So the process in (32) has to involve the meaning of the definite article (i.e. ' 1 ') and the meaning of the null nominal head (the "part-of" relation). The simplest hypothesis one can make is that incorporation of the article first into $\mathrm{P}$ and then into $\mathrm{N}$ tantamounts, semantically, to the composition of the "part-of" relation with the articles meaning:

$$
\begin{aligned}
& \text { a. } \leq \text { o } l=\lambda P \lambda x[\leq(x, l P)] \\
& \text { b. } \leq \text { o } l(\text { ragazzi })=\lambda x[\leq(x, \text { tragazzi })]
\end{aligned}
$$

The result of the composition gives us something that looks for a property to yield a property. For example, applied to ragazzi, yields (33b), i.e. the property of being subgroups of the maximal groups of boys. So far, so good. Now the next step is movement of the N-P-D complex into the higher D. This must involve type shifting, for DP's are argumental. The available options are the usual ones. The unmarked choice for Italian as for English is ' $n$ '. But something like parts of the boys does not have a kindcorrelate, for the same reasons why its overt counterpart doesn't. See example (22) above. So one must resort to ' $\exists$ '. Here is an example:

$$
\begin{aligned}
& \text { a. dei ragazzi }=\exists(\leq 0 \mathrm{l}(\text { boys }))=\lambda P \exists x[\text { boys }(x) \wedge P(x)] \\
& \text { b. dei }=[D \text { part }+ \text { di }+i]=\exists() \leq o l
\end{aligned}
$$


In (34a) we see the result of shifting the type of parts of the boys via $\exists$. The result is (vitually -- see below) identical to an existentially quantified NP. So, an existential quantifier is born; via head raising, interpreted as function composition. What I find interesting about this way of looking at Bare Partitives is that their link to Full Partitives comes out in a transparent and sensible manner. It is now clear why the chosen preposition is the same one as that of Full Partitives. Moreover, the meaning of the new determiner dei is created using exclusively machinery that has strong autonomous support.

\section{Consequences}

In the present section I want to explore consequences of the analysis outlined in the previous section and argue that they provide further support for it. Some of these consequences are specific to languages that have Bare Partitives. Others have to do with crosslinguistic variation and language typology. Let us begin with the discussion of some consequences of the former kind. The basic prediction of our approach is that bare partitives should behave as ordinary existentially quantified DP's. Let us verify that it is indeed so. Consider the following examples:
a. Non ho visto ragazzi
[ only $\neg \exists$ ]
'(I) didn't see boys'
b. Non ho visto un ragazzo
'(I) didn't see a boy'
c. Non ho visto dei ragazzi
'(I) didn't see of-the boys'

$$
\begin{gathered}
\text { [both } \neg \exists \text { and } \exists \neg \text { ] } \\
\text { [ both } \neg \exists \text { and } \exists \neg \text { ] }
\end{gathered}
$$

The partitive DP appears to have the scopal properties of overt indefinites rather than the ones of bare arguments. (35) illustrates this with negation, with respect to which Bare Partitives admit of both wide and naroow scope readings. Similar contrasts can be reproduced for all the tests in (21), i.e. the tests used to illustrate the scopelessness of bare arguments.

Next, indefinites, being existentially quantified, admit of generic interpretations. If bare partitive DP's are interpreted in essentially the same way as overt indefinites, they too ought to admit of generic interpretations. This is indeed so:

(36) a. Dei bravi boy scout aiutano le vecchiette ad attraversare la strada

'Of-the good boy scouts help old ladies cross the road'

b. Degli italiani del sud raramente sono biondi

'Of-the italians from the south rarely are blond'

Sentence (36a) is clearly generic: it quantifies over all good boy scouts. Sentence (36b) shows that Bare Partitives are subject to the quantificational variabily effect typical of indefinites; it says that few southern Italians are blond.

The one feature of bare partitive NP's that differentiates them from ordinary indefinites, is that they have been manifactured via the definite article $i$, which triggers existential presuppositions. Such presuppositions ought to be detectable. The canonical place to look for the crucial evidence is constituted by existential sentences. And indeed this residue of definiteness can be shown to be clearly there in Bare Partitives.

a. Non ci sono folletti
'not there are elfs' [locative or exitential] 

b. Non ci sono folletti capaci di tanto 'Not there are elfs capable of so much'
c. Non ci sono dei folletti
'Not there are of -the elfs'
d. Non ci sono dei folletti capaci di tanto [locative or existential]
'Not there are of-the elfs capable of so much'
[locative or existential]
[existential only]

As is well known, in Italian the definiteness effect typical of English existential sentences is not visible. Italian existential sentences can be interpreted either existentially or locatively; with strong quantifiers only the locative interpretation is possible. Now with bare plurals, we get the two canonical readings of existential sentences, both with or without a coda. With bare partitive DP's we only get both readings in presence of a coda. If there is no coda, only the locative interpretation is possible, as (37c) illustrates. This follows if we assume that the definite article $i$ embedded within $d e i$ does its usual job, viz. that of triggering an existential presupposition. Such an existential presupposition is incompatible with existential readings (see Zucchi 1995, for a recent discussion) and hence only the locative one is available in (37c). In presence of a coda, the existential reading becomes available again, as the coda is outside of the scope of the determiner. The contrast between (37a) and (37c) is very solid. This contrast is difficult to explain if we don't assume that the meaning of $d e i$ is compositionally built out of the meaning of the definite article.

Compositionality is a property of syntactic processes, such as the one we are assuming for the derivation of Bare Partitives, not of idiosynchratic lexical ones, as the standard view on Bare Partitives would have it.

It remains to be seen why singular count nouns are impossible in Bare Partitives (while they are possible with Full Partitives). I do not have a complete explanation for this. But there is line which the present approach suggests that strikes me as fairly plausible. The "part-of" relation involved in Full Partitives can be either ' $\leq$ ' (as in most of the boys) or some other salient relation (as in most of my body). Hence the null nominal head of Full Partitives is to be understood as some kind of variable over a set of natural "part-of" relations. In building Bare Partittives, we have to compose the meaning of the noun with the meaning of the determiner. Hence, it seems reasonable to assume that we have to make a choice. We must pick one relation out of the suitable range of possible ones. The one we pick is the most general, namely ' $\leq$ ' which links pluralities to their subgroups. Whence the restiction to plural and mass nouns: pluralities are the only entities in the domain that have parts (in the sense of ' $\leq$ ') in a proper sense. Sigularities have only themselves as parts. The choice of $\leq$ as the "part-of" relation naturally induces a presupposition of plurality: $\leq$ o $l$

looks for arguments $\mathrm{P}$ such that it doesn't follow from the common ground that $\leq \mathrm{ol}(\mathrm{P})$ is a singleton. That, I suggest, is why bare partitive DP can have only plural or mass nominal heads.

I believe that even some purely syntactic evidence in favour of a head raising analysis of Bare Partitives can be detected. Generally, determiners can be coordinated with each other. The bare partitive determiner dei never can:

a. una o due ragazze
'one or two girls'

b. alcuni ma non molti ragazzi

'some but not all boys'

c. * uno o dei ragazzi 'one or of-the boys'

d. *dei ma non molti ragazzi

' of-the but not many boys' 
The indefinite masculine singular determiner has two forms in Italian un and uno. The choice between the two depends of the nature of the following segment (uno is selected only in front of certain consonant clusters). Un cliticizes phonologically onto the noun. As is well known phonological clitics, in general, do not like to be coordinated. This applies to $u n$. as well. So, one might say that $d e i$ is the plural of $u n$ and this is why it doesn't coordinate. Still, even the article un, can marginally undergo forms of coordination (when its phonological environment is met).

(39) a. ? Non importa se hai visto qualche o un ragazzo

'It doesn't matter if you saw some or a boy'

b. * Non importa se hai visto qualche o dei ragazzi

'It doesn't matter if you saw some or of-the boys'

Yet, as (39) illustrates, dei is even more inhert than the article when it comes to coordination. What might be the reason for such a strong inertia? Compare, e.g., (38b) with (38d). In the first case, we presumably simply have coordination of the lexical category D. In the second case, we are coordinating a basic determiner with a derived one.

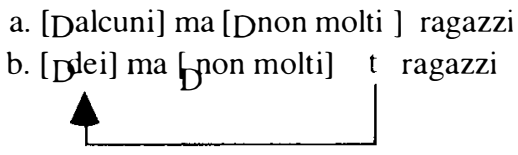

In particular, dei has to be raised from a lower constituent, while molti does not. Whatever analysis one adopts for coordinate structures, $(40 \mathrm{~b})$ is bound to constitute a violation of the Across-the-Board condition on extraction. We thus have a straightforward explanation for why $d e i$ is more passive with respect to coordination than its fellow determiners: because it is syntactically derived via movement.

Let us now turn to some typological considerations. We started out by noticing that Bare Partitives appear to be impossible throughout the Germanic family. This gap seems to be so systematic that it can hardly be accidental. Notice, in particular, that preposition+definite article complexes exist in Germanic. For example, in German the preposition von, which is the one used in Full Partitives, can contract with the definite article: $v o n+d e m==>$ vom. So the ingredients for the formation of Bare Partitives appear to be all there. Yet it doesn't happen. One would like to relate this in some principled manner to other differences in the nominal system, in particular to the freer access that Germanic has to bare nominals. The question is how to cash in on this intuition. How is this generalization to be derived from general properties of grammar in a non circular way?

Our central hypothesis has been that languages vary in the way the category $\mathbf{N}$ (and its phrasal projection) is mapped onto its denotation. We have assumed, in particular, that Germanic languages are characterized by the mapping (10c), repeated here:

$$
\begin{gathered}
\text { NP } \\
{[+ \text { arg +pred] }}
\end{gathered}
$$

Such mapping allows nouns to either be kind denoting or to be predicates. And, as a consequence, the mapping in (41) lets the language free to shift, within the category $\mathrm{N}$, from one of the admissible type to the other (modulo the absence of blockers). This is why plurals can be shifted to kinds and be directly taken as arguments by verbs, without any need of projecting D. Thus, the unavailability of Bare Partitives in Germanic must directly follow from the type assignment in (41). There must be an incompatibility between it and the process of head raising through which Bare Partitives come into existence in Romance. 
It doesn't take too much to see what such incompatibility must be. Head raising in Bare Partitives must be accompanied by type shifting. Raising the "part-of-the" complex into D can only happen if its type is shifted into an argumental one. But in English type shifting can be accomplished within $N$. Hence there is nothing to drive the last crucial step in the derivation of bare partitives, namely raising of $\mathrm{N}$ to $\mathrm{D}$. In fact, we had already noticed, building on Longobardi's work, that $\mathrm{N}$ to $\mathrm{D}$ is unattested throughout Germanic.

Getting more explicit, one might assume a principle of the following sort:

Apply type shifting with as little structure as possible

Principle (42) can be viewed as a straightforward instance of "Avoid Structure", which is turn part of the economical design of grammar, much explored in current research. Such principle has an immediate consequence for Germanic. Within the nominal extended projection, type shifting must occur within the $\mathrm{N}$ projection, as that provides us with the minimum amount of structure necessary to shift, when needed. Consider now the structure that Bare Partitives would come to have in English:

a. [D [NP PART [ of the boys ]] ]

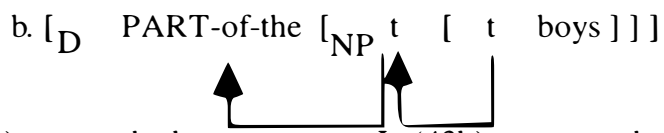

In (43a) we see the base structure. In (43b) we move the lower determiner upwards. Now in Romance, the last step of this derivationis accompanied by type-shifting. In English, this cannot happen. Because of principle (42), type shifting must occur within the NP. But if it does, the semantics becomes incoherent. The upper part is interpreted as the compostion of "part-of" with the, i.e. as $\leq$ o 1 . This is something that looks for a property. But type shifting would map the property boys onto something argumental (of type e or of type GQ, depending on the type shifter). Hence we get a type mismatch, and no way of fixing it (short of stipulation).

$$
\begin{aligned}
& \text { PART-of }- \text { the } \\
& <<\text { et }>,<\text { SHIFT } \text { (boys) })==>\text { Ill formed } \\
& \text { e or GQ }
\end{aligned}
$$

So if in English we raise the lower D to the upper one as indicated in (43b), the semantics crashes. This depends solely from the type assignment chosen by English and on principle (42), which forces type shifting to happen within NP.

The reader may wonder why we couldn't more simply shift the type of (43a) without doing the raising. The category type mapping should allow for that and English does allow bare NP argument. This, however, is impossible in the case at hand for totally independent reasons. Recall that the structure in (43a) contains a null nominal head (to be interpreted as "part-of"). Such a nominal head must be properly lincensed. Hence, a determiner needs to be projected to license (select) it. So there is no way to get bare partitives.

We now have what looks like a good explanation for why, while Germanic and Romance both have very similar Full Partitive structures, only the latter allows for Bare Partitives. In essence, it is a matter of economy. Bare partitives arise through a syntactic process whose semantic counterpart involves type shifting. The category-type association of Germanic is such that shifting can, and hence must, apply without syntactic raising.

One question that remains concerns the status of Bare Partitives within the Romance language family. If in Romance, determiners can raise to $P$ and then, eventually to the higher D position of Partitives, why is it that this doesn't happen in every language with the same category-type mapping as Italian, i.e. in every Romance language? The question, in 
$\mathrm{NP}$
$[+\arg +$ pred $]$

Without articles:
i. Bare plurals/mass for
kind reference
ii. Bare singular with definite or
definite readings
iii. Mass/count otherwise as in type (b)
With articles:
i. Bare plural/mass for
for kind reference
ii. No bare singular
iii. Mass/count otherwise as in type (b)

I call this the Nominal Mapping Parameter.The setting of the NMP appears to be learnable in principle through its overt morphosyntactic manifestations, by means of direct positive evidence. Hence it looks a priori as (im)plausible as any other parameter that has been proposed. The potentially interesting aspect of this proposal is how naturally it accounts for some important clusterings of properties of the nominal systems across languages. The guiding idea is just this: if nominal categories are argumental, they can occur as arguments without having to project extra syntactic structure. If not, syntactic structure that makes them argumental (i.e. the category D) must be projected. In languages of the mixed kind (45c), nouns can be shifted from predicative to argumental (and back), subject to a blocking effect. Blockers are overt morphemes (e.g., the articles) that have a type shifter as its meaning. This results in the two subsystems: Germanic (which has articles and has a more restricted ditribution of bare arguments) vs. Slavic (which lacks articles and allows for a broader spectrum of uses of bare arguments).

In this set up, we have sketched a Neocarlsonian view of bare plurals in English and argued that this is not only viable (contra what is assumed in much recent work) but quite enlightening. In particular, it makes us understand why if nouns can be thought of as being associated with a kind, they appear to be scopeless; if they cannot, they behave like overt indefinites with respect to scope. This is simply due to the fact that (given what

blockers are available in English) when ' $\mathrm{n}$ ' is undefined, one resorts to ' $\exists$ '. We contrasted this with the situation in Romance where bare argument can only be obtained by projecting a null determiner. Such a null determiner is subject to conditions of licensing and identification, which govern its availability and distribution. Thus in these languages, type shifting must be mediated by the projection of extra syntactic structure. This has consequences for proper names. They are of category $\mathrm{N}$, but their (unmarked) semantic type is referential (viz. e). In Romance, this clashes with the general setting for $\mathbf{N}$, and forces them to be promoted to the status of (intransitive) determiners. This manifests itself in a pattern of $\mathrm{N}$ to $\mathrm{D}$ raising. Our theory makes it obvious why such a process is impossible in languages with a different category-type association.

This takes us to the issue of partitives. Full Partitives are analysed in a fairly canonical way, by positing a null nominal head which hosts a relational noun like "part" or something of that sort. The novel aspect of the present proposal consists in the analysis of Bare Partitives, which are derived from the same structure of Full Partitives. More specifically Bare Partitives are syntactically derived via a process of raising of the $P+D$ complex of Full Partitives first into the null $\mathrm{N}$ and then into the higher D. This last step must be semantically accompanied by a shifting of the meaning of the restriction of Full Partitives into an argument. In this way, a new determiner with an existential meaning is created. Both the language particular and typological properties of this construction are seen to derive naturally from the proposed analysis (down to a considerable level of detail). The absence of Bare Partitives in some of the Romance languages follows from blocking. Their absence in languages with a category-type assignment different from the Romance one follows from "Avoid Structure". One doesn't project higher syntactic categories (and move 
more technical terms, is the following. We are assuming that the category-type assignment is the same throughout Romance. This explains the restricted distribution of bare arguments in such languages. In particular, Italian and Spanish appear to be very similar on this score. They both restrict bare arguments, essentially, to lexically governed positions; they both have Full Partitives. But Italian has Bare Partitives and Spanish does not. We have assumed that what triggers the formation of Bare Partitives is a clitic feature CL that definite determiners may have. Spanish and Italian are fairly similar in their clitic system. If so, what prevents raising of the determiner in Spanish (and similarly for Catalan and Portuguese)? Or, equivalently, what prevents the feature $+\mathrm{CL}$ from being instantiated on Spanish determiners?

Here is the answer that stems from our approach. Suppose such a feature was indeed instantiated on the definite article in Spanish, triggering raising of $D$ to $P$ in a structure analogous to (32). Then, to get the appropriate checking configuration, the $P+D$ complex would have to raise to the upper $\mathrm{D}$. The last step ( $\mathrm{N}$ to $\mathrm{D}$ ) crucially inolves type shifting: the type of the noun (which, in Romance, is predicative) has to be turned into an argumental one. Type-shifting is a last resort. In our terms, this means that it is inhibited by the presence of blockers. Any word or morpheme with the same semantics as the relevant type shifting operation qualifies as a blocker. The type-shifting operation relevant to Bare Partitive formation is ' $\exists$ '. The singular indefinite article, we have argued, has ' $\exists$ ' as (one of its) meaning(s). Now, Spanish, as is well known, has an inequivocably plural form of the indefinite article, viz. unos. Clearly, this will have the same meanings (over the plural

domain) as its singular counterpart. These include ' $\exists$ '. But then use of ' $\exists$ ' as a type shifter will be blocked in Spanish. So, if the feature $+\mathrm{CL}$ is instantiated on Spanish definite determiners, triggering Bare Partitive formation, the derivation will crash. For the last step, which must involve type-shifting, will be blocked by the presence of the plural article. Thus, the absence of Bare Partitives in languages with the same type assignment as Italian, like Spanish, appears to follow from quite general principles.

\section{Conclusions}

What are the main ideas we have put forth? Our starting point has been a certain view of how the domain of interpretation is structured and how the denotation of mass and count nouns is set up. The meaning of mass nouns is viewed as the neutralization of the singular/plural contrast. Kinds are analysed as functions from situations into maximal plural individuals that comprise all the instances of the kind. These ideas are probably not so crucial to the rest of my proposal. They help in setting the system up in an arguably simple and constrained way. The burden of explanation in the chosen area of inquiry lies on giving up a widely shared idea, viz. that the syntax-semantics map is completely universal. I have proposed, instead, that the denotation of members of the syntactic category $\mathbf{N}$ can vary in a very limited way. The options are the following. Nouns can be uniformely kind denoting, or uniformely predicative or mixed. Languages have access to a small set of type-shifting operations that can be used freely up to consistency with the category-type correspondence that holds in the language. The basic system we get is summarized in the following table:

$$
\begin{aligned}
& \text { a. } \mathrm{NP} \\
& {[+ \text { arg - pred] }} \\
& \text { b. NP } \\
& \text { [-arg + pred] }
\end{aligned}
$$

i. Free bare arguments

ii. No plural

iii. Obligatory classifiers

i. No bare arguments

(or ECP-like distribution)

ii. Plural only for count N's

iii. Obligatory classifiers with mass
Chinese

Romance 
material into them) if type shifting can be applied with less structure. The present view of the syntax-semantics map enables us to make sense of the intuition that the absence of bare partitives in Germanic is a matter of economy.

\section{Endnotes}

* Besides Salt, versions of this paper have been presented at MIT, Going Romance, The University of Florence. I thank all of those audiences for their comments. Special thanks are also due to Pino Longobardi and to Carlo Cecchetto, Teresa Guasti and Andrea Moro.

1 This view of plurals has been argued (see, e.g., Schwarzchild 1996) to run into difficulties in connection with determiners like no. I refer to Chierchia (1995) for discussion.

${ }^{2}$ Notice that some care is required in spelling out these assumptions, for $\mathrm{UW}^{\mathrm{W}}$ is strictly bigger than $U$ and yet we want to put enough members of $\mathrm{UW}^{\mathrm{W}}$ in $\mathrm{U}$ to sustain a compositional semantics for kind denoting terms. See Chierchia and Turner (1988) for relevant discussion.

${ }^{3}$ Whether a bareplural is interpreted universally or existentially in generic contexts will actually depend on whether it winds up in the restriction or the scope of the generic operator. See Krifka et al. (1995) and references therein for discussion.

${ }^{4}$ Many criticisms have been levelled against Carlson's theory. Some have to do with the relation of bare plurals to singular definite generics like the lion. Others have to do with their anaphoric behavior. Yet others, with their behavior in there sentences. See Krifka et al (1995) and references therein for discussion. Chierchia (1996) tries to make a case that most or all of such criticisms have no force against the Neocalrsonian theory sketched in the text.

5 This leaves us with a violation of Mirror Image. I have nothing to offer on this score. If the principle is valid, a local rearrangement at the phonetic interface has to be assumed.

\section{References}

Abney, S. (1987) The English Noun Phrase in its Sentential Aspect, Ph. D. Diss., MIT, Cambridge, Mass.

Baker, M. (1988) Incorporation: A Theory of Grammatical Function Changing, University of Chicago Press, Chicago.

Cardinaletti, A. and G. Giusti (1992) "Partitive Ne and the QP Hypothesis. A Case Study" in E. Fava (ed) Proceedings of the XVII Meeting of Generative Grammar, Rosenberg \& Sellier, Turin.

Carlson, G. (1977) Reference to Kinds in English, Ph. D. Dissertation, University of Massachusetts at Amherst; distributed by Indiana University Linguistic Club. Published in 1980 by Garland Inc., New York.

Carlson, G. (1989) "The Semantic Composition of English Generic Sentences" in G. Chierchia, B.H.Partee and R. Turner (eds) Properties, Types and Meaning, vol. II, Kluwer, Dordrecht.

Chierchia, G. (1984) Topics in the Syntax and Semantics of Infinitives and Gerunds, Ph. D. Diss., The University of Massachusetts at Amherst. Published in 1989 by Garland Inc., New York. Ref kinds

Chierchia, G. (1995a) Dynamics of Meaning. The University of Chicago Press, Chicago.

Chierchia, G. (1995b) Plurality of Mass Nouns and the Notion of Semantic Parameter, DIPSCO Working Papers in Linguistics, H. San Raffaele, Milan; a revised version to appear in S. Rothstein (ed.) Events in Grammar, Kluwer, Dordrecht, forthcoming. 
Chierchia, G. (1996) Reference to Kinds across Languages, unpublished manuscript, University of Milan, Milan

Chierchia, G. and R. Turner (1988) "Semantics and Property Theory", Linguistics and Philosophy, 11:261-302.

Cinque, G. (1990) Types of $A^{\prime}$ Dependencies, MIT Press, Cambridge, Mass.

Contreras, H. (1986) "Spanish Bare NP's and the ECP" in I. Bordelois, H. Contreras and K. Zagona (eds) Generative Studies in Spanish Syntax, Foris, Dordrecht.

Delfitto, D. and J. Schroten (1992) Bare Plurals and the Number Affix in DP's, OTS Working Papers, Utrecht.

Diesing, M. (1992) Indefinites, MIT Press, Cambridge, Mass.

Fox, D. (1995) "Economy and Scope", Natural Language Semantics, 3: 283-341.

Kratzer, A. (1995) Scope or Pseudoscope? Are there Wide Scope Indefinites?, unpublished manuscript, University of Massachusetts at Amherst; a revised version to appear in S. Rothstein (ed) Events in Grammar, Kluwer, forthcoming.

Krifka, M. (1988) "The Relational Theory of Genericity" in M. Krifka (ed.) Genericity in Natural Language, SNS Bericht 88-42, University of Tuebingen

Krifka, M. (1995) "Common Nouns: A Contrastive Analysis of Chinese and English" in G. Carlson and F.J. Pelletier (eds.) The Generic Book, The University of Chicago Press, Chicago.

Krifka, M. et al. (1995) "Genericity: an Introduction" in G. Carlson and F.J. Pelletier (eds) The Generic Book, The University of Chicago Press, Chicago.

Ladusaw, B. (1982) "Semantic Constraints and the English Partitive Construction", in D. Flickinger, M. Macken and N. Wiegand (eds.) Proceedings of WCCFL I, Stanford University, Stanford Ca.

Landman, F. (1989) "Groups I", Linguistics and Philosophy, 12:559-605.

Landman, F. (1991) Structures for Semantics, Kluwer, Dordrecht.

Link, G. (1983) "The Logical Analysis of Plural and Mass Nouns: a Lattice Theoretic Approach", in R. Bauerle, C. Schwarze and A. von Stechow (eds.) Meaning, Use and Interpretation of Language, de Gruyter, Berlin.

Longobardi, G. (1994) "Reference and Proper Names: a Theory of N-Movement in Syntax and Logical Form", Linguistic Inquiry 25:609-665.

Longobardi, G. (1996) "The Syntax of N-Raising: a Minimalist Theory, OTS Working Papers, Utrecht.

Ojeda, A. (1993) Linguistic Individuals, CSLI, Stanford.

Partee, B.H. (1987) "Noun Phrase Interpretation and Type-Shifting Principles" in J. Groenendijk et al. (eds.) Studies in Discourse Representation Theory and the Theory of Generalized Quantifiers, Foris, Dordrecht.

Reinhart, T. (1995) "Quantifier Scope", OTS Working Papers in Linguistics, Utrecht; forthcoming in Linguistics and Philosophy.

Rizzi, L. (1986) "Null Objects in Italian and the Theory of Pro", Linguistic Inquiry, 17: $501-558$.

Rizzi (1996) "On the Fine Structure of the Left Periphery", ms., University of Geneva.

Schwarzchild, R. (1996) Pluralities, Kluwer, Dordrecht.

Selkirk, E. (1977) "Some Remarks on NP Structure" in P. Culicover, T. Wasow and A. Akmajan (eds.) Formal Syntax, Academic Press, N.Y.

Sharvy (1980)"A More General Theory of Definite Descriptions", The Philosophical Review, 89: 607-624.

Torrego, E. (1989) "Unergative-Unaccusative Alternations in Spanish", MIT Working Papers, Cambridge, Mass.

Winter, Y.(1996) "Choice Functions and the scopal Semantics of Indefinites", OTS Working Papers, Utrecht.

Zucchi, A. (1995) "The Ingredients of the Definitness Effect". Natural Language Semantics, 3: 33-78. 